\title{
Sensing properties of germanate and tellurite glass optical fibres
}

\author{
Hongxia Li ${ }^{* a}$, Joris Lousteau ${ }^{b}$, Rui Suo ${ }^{c}$, Xin Jiang ${ }^{b}$, William N. MacPherson ${ }^{\mathrm{a}}$, Henry T. Bookey ${ }^{\mathrm{d}}$, \\ James S. Barton ${ }^{\mathrm{a}}$, Ajoy K. Kar ${ }^{\mathrm{d}}$, Lin Zhang ${ }^{\mathrm{c}}$, Animesh Jha ${ }^{\mathrm{b}}$, Ian Bennion ${ }^{\mathrm{c}}$ \\ aApplied Optics and Photonics, Heriot-Watt University, Edinburgh, EH14 4AS, UK; \\ ${ }^{\mathrm{b}}$ Institute for Materials Research, University of Leeds, Clarendon Road, Leeds LS2 9JT, UK; \\ ${ }^{\mathrm{c}}$ Photonics Research Group, Aston University, Birmingham, UK, B47ET; \\ ${ }^{\mathrm{d}}$ Nonlinear Optics Group, Heriot-Watt University, Edinburgh, EH14 4AS, UK;
}

\begin{abstract}
Strain and thermal sensitivities of germanate and tellurite glass fibres were measured using a fibre Fabry-Perot (FFP) interferometer and fibre Bragg gratings (FBG). The strain phase sensitivity for germanate and tellurite fibre were $5900 \times 10^{3} \mathrm{rad} / \mathrm{m}$ and $5600 \times 10^{3} \mathrm{rad} / \mathrm{m}$ respectively at a central wavelength of $1540 \mathrm{~nm}$ using FFP interferometer, which is consistent with the value of $1.22 \mathrm{pm} / \mu \varepsilon$ obtained for a germanate fibre FBG. The Young's modulus for germanate and tellurite fibre were also measured to be $58 \mathrm{GPa}$ and $37 \mathrm{GPa}$. The thermal responses of germanate fibre were examined as 24.71 and $16.80 \mathrm{pm} /{ }^{\circ} \mathrm{C}$ at $1540 \mathrm{~nm}$ and $1033 \mathrm{~nm}$ wavelength using the FBG.
\end{abstract}

Keywords: Fabry-Perot cavity, Bragg grating, interferometer, strain, Young's modulus, phase sensitivity

\section{INTRODUCTION}

Germanate and tellurite glass fibres are of interest both in fundamental research and also in optical device fabrication. The high refractive index and optical nonlinearity, the resistance to corrosion, low melting temperature and its good transmission properties in the visible-infrared $(0.35-6 \mu \mathrm{m})$ [1] make them promising candidate for bio/chemical and gas sensing [2-3], nonlinear optical signal processing [4] and optical amplifier and laser devices[5-6]. Among these applications, the strain and thermal optical properties of fibres are important parameters which are necessary to model, design, and operate fibre sensors, lasers and amplifiers.

In this paper, we report strain sensitivity measurements of fibres drawn from germanate glass $\left(\mathrm{mol}^{2}\right)$ : $56 \mathrm{GeO}{ }_{2}-31 \mathrm{PbO}-$ $9 \mathrm{Na}_{2} \mathrm{O}-4 \mathrm{Ga}_{2} \mathrm{O}_{3}$ and tellurite glass $(\mathrm{mol} \%): 75 \mathrm{TeO}_{2}-15 \mathrm{ZnO}-10 \mathrm{Na}_{2} \mathrm{O}$. The strain responses of the GPNG and TZN glass fibres and their Young's modulus were determined using two methods: (i) a fibre Fabry-Perot (FFP) interferometer formed by splicing glass fibre with singlemode silica fibre on both sides and (ii) a fibre Bragg gratings (FBG) fabricated by $800 \mathrm{~nm} f \mathrm{~s}$-inscription. The thermal responses of germanate fibre was also examined using the fibre Bargg grating. All the experimental measurement results were compared with values calculated using available published data for glasses of similar compositions.

\section{EXPERIMENT AND RESULTS}

\subsection{FFP interferometer principle and setup}

Short length FFP cavities were formed by splicing two singlemode silica fibres onto both ends of the soft glass fibres using an asymmetric fusion splicing technique as introduced in [7]. The experiment setup is shown in figure 1. Broadband light from an erbium-doped ASE source was coupled into the FFP by a $2 \times 2$ single-mode fibre coupler. The phase of the interference fringes is given by:

$$
\phi=(2 \pi / \bar{\lambda}) \times 2 n L
$$

*h190@hw.ac.uk; phone +44(0)131 451 3063; fax +44(0)131 451 3136; www.aop.hw.ac.uk

20th International Conference on Optical Fibre Sensors, edited by Julian Jones, Brian Culshaw, Wolfgang Ecke, José Miguel López-Higuera, Reinhardt Willsch, Proc. of SPIE Vol. 7503, 750320 (c) 2009 SPIE · CCC code: 0277-786X/09/\$18 - doi: 10.1117/12.835317 
where $\mathrm{n}$ is the refractive index of the core of germanate or tellurite fibre, $\bar{\lambda}$ is the mean wavelength and $\mathrm{L}$ is the FFP cavity length. The sensitivity of the optical phase to strain is used to determine the strain response of germanate and tellurite fibre.

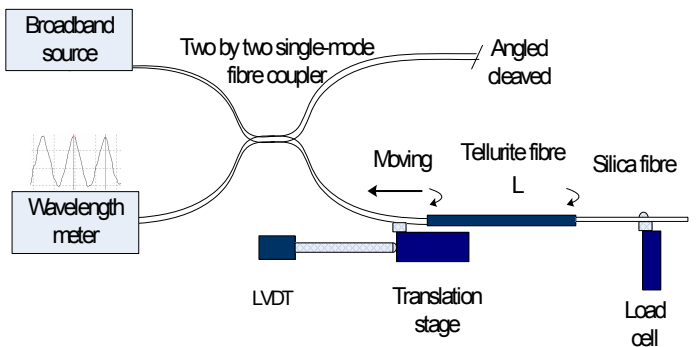

Fig.1. Scheme for strain response experiment of tellurite fiber Fabry-Perot cavity

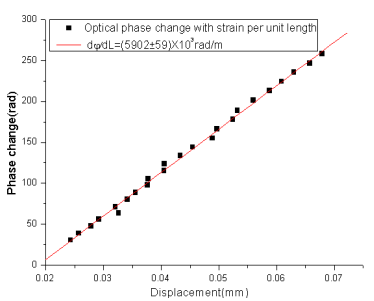

(a)

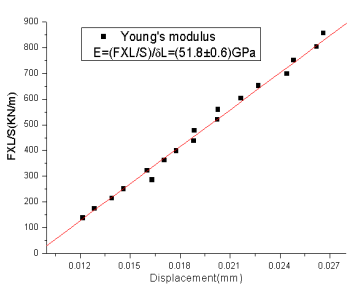

(b)

Fig. 2. Optical phase change versus elongation of germanate fiber at $\sim 1540 \mathrm{~nm}$ (a) and (applied stress $\times$ fibre length) versus fibre elongation, Yong's modulus is equal to the slope of the linear fit (b).

In the experiment, the germanate and tellurite fibre samples to be strained were configured as a low finesse FFP interferometer with two silica fibres spliced on both sides as shown in figure 1. One side of silica fibre without buffer was attached by glue (no slippage was observed during the experiments due the glue hardness) to a Melles-Griot Nanostepper translation stage which was used to longitudinally strain the germanate or tellurite fibres. A precision displacement sensor (LVDT) with $\sim 1 \mu \mathrm{m}$ resolution was used to measure the movement independently. The other end of silica fibre without buffer was glued to a $2 \mathrm{Kg}$ load cell to directly monitor the load applied to the soft glass fibre. In this manner it was possible to measure the phase shift per unit displacement caused by stretching the germanate or tellurite fibre through the translation stage movement. An erbium amplified spontaneous emission (ASE) source with a total output power of $30 \mathrm{~mW}$ and a spectral bandwidth of around $35 \mathrm{~nm}$ was used. At each movement set-point, the wavelength position of one interference fringe peak was recorded and the displacement was measured using LVDT at the same time. The fringe shifts were observed and recorded by a WA-7600 wavemeter.

\subsection{Results of germanate and tellurite fibre strain sensitivity and Young's modulus}

Due to the fused silica fibre is also stretched in the experiment, first we calibrated the strain of the silica fibre with the load cell output using two different lengths singlemode silica fibres between the load cell and the nanostepper translation stage and measuring the amplifier output versus displacement. Then several lengths of germanate and tellurite FFP were used to determine the sensitivity of interferometric phase to strain. By recording the wavelength shift of one interference fringe peak as a function of displacement, and dividing it by the free spectral range expressed in wavelength, the plot of germanate and tellurite fibre phase-displacement were obtained and the phase change per uint length elongation of the fibre were derived from the slope as shown in figure 2(a) and figure 3(a). From the measurements of the displacement and the applied force, the Young's modulus of germanate and tellurite fibre were inferred as the gradient of applied stress multiplied by length versus displacement, as shown in figure 2(b) and figure 3(b). The average value of the strain sensitivity and Young's modulus for germanate fibre were $(5900 \pm 300) \times 10^{3} \mathrm{rad} / \mathrm{m}$ at $1540 \mathrm{~nm}$ and $(52 \pm 2) \mathrm{GPa}$ respectively, for tellurite fibre were $(5600 \pm 200) \times 10^{3} \mathrm{rad} / \mathrm{m}$ and $(37 \pm 3) \mathrm{GPa}$ respectively.

\subsection{Results of germanate fibre strain and thermal sensitivity using FBG (fibre Bragg grating)}

In order to verify that the FFP interferometer experiment setup was valid and the results meaningful, we measured the strain sensitivity of germanate fibre using a fibre Bragg grating. The FBG structures were produced in the germanate fibres using fs-inscription through a custom-designed phase mask with a period of $1697.33 \mathrm{~nm}$ [8]. The $2^{\text {nd }}$ and $3^{\text {rd }}$ order Bragg resonance of the germanate fibre was observed at $1540 \mathrm{~nm}$ and $1033 \mathrm{~nm}$ wavelength. The strain response of germanate fibre was also examined by applying longitudinal strain to the grating fibres. The average strain sensitivity and normalized strain sensitivity of the $2^{\text {nd }}$ order germanate fibre Bragg resonance at $1540 \mathrm{~nm}$ were measured to be $(1.22 \pm 0.04) \mathrm{pm} / \mu \varepsilon$ and $0.792 \times 10^{-6} / \mu \varepsilon$ respectively, as shown in fig. 4 (a). Compare with the results of $5900 \times 10^{3} \mathrm{rad} / \mathrm{m}$ and $0.791 \times 10^{-6} / \mu \varepsilon$ from strain applied to the fibre configured as a Fabry-Perot interferometer, it can be seen that the strain responses of germanate glass fibre from the FBG and Fabry-Perot interferometer measurement were consistent with each other with only $0.13 \%$ difference in the normalized strain sensitivity. 
The thermal response of germanate fibre was also examined by subjecting the grating fibers to elevated temperatures. The wavelength shifts of the $2^{\text {nd }}$ and $3^{\text {rd }}$ order germanate fibre Bragg resonances at $1540 \mathrm{~nm}$ and $1033 \mathrm{~nm}$ versus the temperature changes from $10{ }^{\circ} \mathrm{C}$ to $70{ }^{\circ} \mathrm{C}$ with increments of $5{ }^{\circ} \mathrm{C}$ are shown in fig. 4 (b). The measured thermal responses are 24.71 and $16.80 \mathrm{pm} /{ }^{\circ} \mathrm{C}$, respectively. The thermal response of $\mathrm{FBG}$ can be expressed as:

$$
\Delta \lambda / \Delta T=\lambda_{B}\left[(1 / \Lambda) \cdot(d \Lambda / d T)+(d n / d T) \cdot\left(1 / n_{e f f}\right)\right]=\lambda_{B}\left(\alpha+\beta / n_{e f f}\right)
$$

Using the thermal expansion coefficient value $\alpha=1.09 \times 10^{-5} /{ }^{\circ} \mathrm{C}$, the thermo-optic coefficient value $\beta=9.0 \times 10^{-6} /{ }^{\circ} \mathrm{C}$ in [11], and $\mathrm{n}_{\text {eff }}=1.8156$, the thermal sensitivity at 1540 and $1033 \mathrm{~nm}$ can be calculated as 24.43 and $16.39 \mathrm{pm} /{ }^{\circ} \mathrm{C}$ respectively. From the above calculation, the experimental thermal responses of germanate fibre are in good agreement with the theoretical ones, which also consistent with thermal phase sensitivity result of $116 \mathrm{rad} \mathrm{m}^{-1} \mathrm{~K}^{-1}$ at $1540 \mathrm{~nm}$ from applied elevating temperature to the fibre configured as a Fabry-Perot interferometer [7].

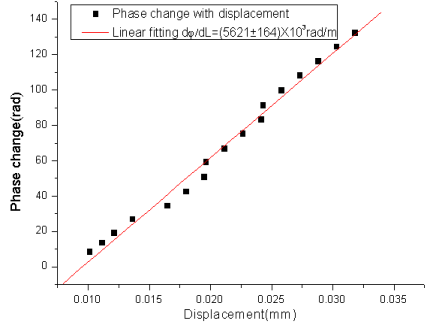

(a)

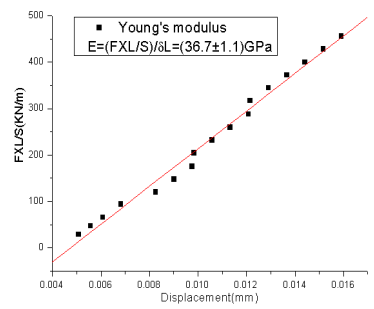

(b)

Fig. 3. Optical phase change versus elongation of tellurite fiber at $\sim 1540 \mathrm{~nm}$ (a) and (applied stress $\times$ fibre length) versus fibre elongation, Yong's modulus is equal to the slope of the linear fit (b).

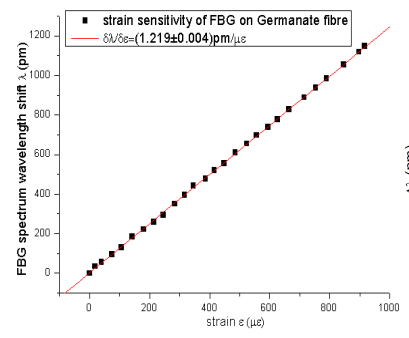

(a)

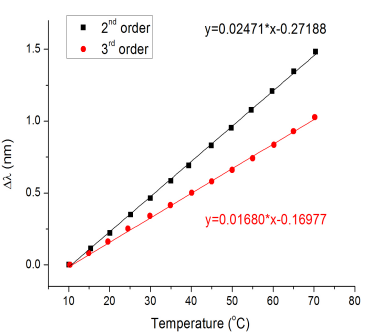

(b)

Fig. 4. The germanate FBG strain sensitivity at $\sim 1540 \mathrm{~nm}$ (a) and thermal sensitivity at $\sim 1540 \mathrm{~nm}$ and $\sim 1033 \mathrm{~nm}$

\section{DISCUSSION}

The strain responses were calculated by using parameters of materials with similar compositions as germanate or tellurite glass fibres. Using a first order theory of elasticity and the photoelastic effect, and assuming that the fibre is elastic and mechanically homogeneous, the optical phase change per unit strain per unit fibre length of the Fabry-Perot interferometer can be express as:

$$
\Delta \phi / \varepsilon L=\Delta \phi / \Delta L=(2 n \pi / \lambda)\left\{1-\left(n^{2} / 2\right) \times\left[(1-\mu) p_{12^{-}} \mu p_{11}\right]\right\}
$$

Strain sensitivity of FBGs can be expressed as:

$$
\Delta \lambda_{B} / \varepsilon=\lambda_{B} \times\left\{1-\left(n^{2} / 2\right) \times\left[(1-\mu) p_{12^{-}} \mu p_{11}\right]\right\}
$$

Then the normalized strain sensitivity of the fibre from F-P interferometer and FBGs can be expressed as:

$$
(1 / \beta) \times(\Delta \phi / \Delta L)=\left(1 / \lambda_{B}\right) \times\left(\Delta \lambda_{B} / \varepsilon\right)=1-\left(n^{2} / 2\right) \times\left[(1-\mu) p_{12}-\mu p_{11}\right]
$$

where $\beta$ is the propagation constant of the mode in the fibre, $\varepsilon$ is the longitudinal strain applied to the fibre, $\mu$ is Poisson's ratio, $p_{11}$ and $p_{12}$ are the strain-optic coefficients. Using $p_{11}=0.225, p_{12}=0.235$ and $\mu=0.232$ for germanate glass with composition (mol\%) of $30 \mathrm{PbO}-10 \mathrm{Bi}_{2} \mathrm{O}_{3}-60 \mathrm{GeO}_{2}$ from [9], the optical phase change with strain of F-P interferometer and strain sensitivity of FBG at $1540 \mathrm{~nm}$ can be calculated as $6318 \times 10^{3} \mathrm{rad} / \mathrm{m}$ and $1.270 \mathrm{pm} / \mu \varepsilon$. The normalized strain sensitivity of germanate fibre at $1540 \mathrm{~nm}$ can be derived with the value of $0.8243 \times 10^{-6} / \mu \varepsilon$, which is $4 \%$ higher than the value from experimental measurement. Table 1 gives the strain properties of germanate and tellurite fibre from optical measurement and theoretical calculation.

From Table 1, we can conclude that the Fabry-Perot experiments show that the phase change per unit length per unit strain $(\mathrm{d} \phi / \mathrm{dL})$ in tellurite fiber is $4.8 \%$ smaller than in the germanate fiber; this proportion is consistent with values calculated using published data for fibres of similar compositions, although the absolute values from experiments are $\sim 6.6 \%$ lower than those derived from published properties. The difference between these experimental and predicted values may be due to the slightly different glass compositions being compared. Even though tellurite fibre has a higher refractive index, its effect is offset by a larger strain-optic term, which reduces the phase change under strain. However, if we consider the phase change per unit length per unit stress $\left(\frac{1 d \phi}{E} d L\right)$, the smaller Young's modulus of tellurite fibre compared to germanate leads to a larger response by a factor in the ratio of the measured moduli (52/37) i.e. $~ 1.4$. Hence tellurite fibre would be advantageous as a load sensing element. 
Table 1. Strain properties of GPNG and TZN fiber from optical measurement and theoretical calculation

\begin{tabular}{|c|c|c|c|c|}
\hline & & & GPNG & $\mathrm{TZN}$ \\
\hline \multirow{5}{*}{$\begin{array}{c}\text { Optical } \\
\text { measurement }\end{array}$} & \multicolumn{2}{|c|}{ F-P cavity $\mathrm{d} \phi / \mathrm{dL}(\mathrm{rad} / \mathrm{m})$} & $5900 \times 10^{3}$ & $5600 \times 10^{3}$ \\
\hline & \multicolumn{2}{|c|}{ FBG d $\lambda_{\mathrm{B}} / \varepsilon(\mathrm{pm} / \mu \varepsilon)$} & 1.22 & - \\
\hline & \multirow{2}{*}{$\begin{array}{c}\text { Normalized strain } \\
\text { sensitivity }(/ \mu \varepsilon)\end{array}$} & F-P & $0.792 \times 10^{-6}$ & $0.676 \times 10^{-6}$ \\
\hline & & FBG & $0.791 \times 10^{-6}$ & - \\
\hline & \multicolumn{2}{|c|}{ Young's modulus (GPa) } & 52 & 37 \\
\hline \multirow{7}{*}{ Calculation } & \multicolumn{2}{|c|}{$\mu$} & $0.282[9]$ & $0.233[10]$ \\
\hline & \multicolumn{2}{|l|}{$p_{11}$} & $0.225[9]$ & $0.0074[10]$ \\
\hline & \multicolumn{2}{|c|}{$p_{12}$} & $0.235[9]$ & $0.187[10]$ \\
\hline & \multicolumn{2}{|c|}{$\mathrm{d} \phi / \mathrm{dL}(\mathrm{rad} / \mathrm{m})$} & $6318 \times 10^{3}$ & $6018 \times 10^{3}$ \\
\hline & \multicolumn{2}{|c|}{$\mathrm{d} \lambda_{\mathrm{B}} / \varepsilon(\mathrm{pm} / \mu \varepsilon)$} & 1.270 & 1.090 \\
\hline & \multicolumn{2}{|c|}{ Normalized strain sensitivity $(/ \mu \varepsilon)$} & $0.8243 \times 10^{-6}$ & $0.7080 \times 10^{-6}$ \\
\hline & \multicolumn{2}{|c|}{ Young's modulus (GPa) } & $63.64[11]$ & $37.15[12]$ \\
\hline
\end{tabular}

\section{CONCLUSIONS}

The optical phase sensitivity to strain and the normalized strain sensitivity of germanate glass fibre were measured as $(5900 \pm 300) \times 10^{3} \mathrm{rad} / \mathrm{m}$ and $0.791 \times 10^{-6} / \mu \varepsilon$ respectively at $1540 \mathrm{~nm}$ by a Fabry-Perot cavity interferometer, which is consistent with the value of $0.792 \times 10^{-6} / \mu \varepsilon$ from $2^{\text {nd }}$ order fibre Bragg grating measurement. The Young's modulus was measured to be 52GPa. The strain sensitivity and Young's modulus of tellurite fibre were measured as $(5600 \pm 200) \times 10^{3} \mathrm{rad} / \mathrm{m}$ and $37 \mathrm{GPa}$. The thermal responses of the $2^{\text {nd }}$ and $3^{\text {rd }}$ order germanate fibre Bragg resonances were measured as 24.7 and $16.8 \mathrm{pm} /{ }^{\circ} \mathrm{C}$ respectively. All the experimental measurement results are in good agreement with values calculated using available published data for glasses of similar compositions.

Acknowledgements: The authors wish to thank the UK Engineering and Physical Sciences Research Council Grant Nos. EP/C515226/1 , EP/C515218/1 for support, including a studentship for H. Li.

\section{REFERENCES}

1. S. Shen, A. Jha, X. Liu, M. Naftaly, K. Bindra, H. J. Bookey, and A. K. Kar, "Tellurite glasses for broadband amplifiers and integrated optics," J. Am. Ceram. Soc. 85, 1391-1395 (2002).

2. T. Uemura, K. Nishida, M. Sakakida, K. Ichinose, S. Shimoda, and M. Shichiri, "Non-invasive blood glucose measurement by Fourier transform infrared spectroscopic analysis through the mucous membrane of the lip: application of a chalcogenide optical fiber system," Frontiers Med. Biol. Eng. 9, 137-153 (1999).

3. J. Mulrooney, J. Clifford, C. Fitzpatrick and E. Lewis, "Detection of carbon dioxide emissions from a diesel engine using a mid-infrared optical fibre based sensor," Sensors and Actuators A: Physical. 136, 104-110 (2007).

4. K. S. Bindra, H. T. Bookey, A. K. Kar, B. S. Wherrett, X. Liu, and A. Jha, "Nonlinear optical properties of chalcogenide glasses: Observaton of multiphoton absorption," Appl. Phys. Lett. 79, 1939-1941(2001).

5. A. Mori, H. Masuda, K. Shikano and M. Shimizu, "Ultra-wide-band tellurite-based fiber Raman amplifier." J. Lightwave Technol. 21, 1300-13106 (2003).

6. A. Céreyon, B. Champagnon, V. Martinez, L. Maksimov, O. Yanush, V.N. Bogdanov, "xPbO-(1-x)GeO2 glasses as potential materials for Raman amplification," Optical Materials. 28, 1301-1304 (2006).

7. H. Li, J. Lousteau, W. N. MacPherson, X. Jiang, H. T. Bookey, J. S. Barton, A. Jha, A. K. Kar, "Thermal sensitivity of tellurite and germanate optical fibers," Opt. Express. 15, 8857-8863 (2007).

8. R. Suo, J. Lousteau, H.Li, X.Jiang, K.Zhou, L.Zhang,W. N. MacPherson, H. T. Bookey, J. S. Barton, A. K. Kar, A. Jha, I.Bennion, "Fiber Bragg gratings inscribed using $800 \mathrm{~nm}$ femtosecond laser and a phase mask in single- and multi-core mid-IR glass fibers," Opt.Express. 17, 7540-7548 (2009)

9. I. Rabukhin, "Concentration dependences of elastooptic coefficients of germanate glasses containing lead and bismuth oxides," Glass and Ceramics 37, 87-90 (1995).

10. K. Ghatak, K. Thyagarajan, Optical Electronics, (Cambridge University Press), Chap.16, 1989, p503

11. S. S. Bayya, G. D. Chin, J. S. Sanghera, and I. D. Aggarwal, "Germanate glass as a window for high energy laser systems," Opt. Express 14, 11687-11693 (2006).

12. EL-Adawy and R. EL-Mallawany, "Elastic modulus of tellurite glasses," J. Mater. Sci. Lett. 15, 2065-2067 (1996). 